\title{
Otomatisasi Sistem Inventarisasi Barang di Sekolah: Studi pada SD Negeri Sidorejo Lor 06, Salatiga
}

\author{
Anis Setia Wati ${ }^{1}$, Evi Maria ${ }^{2 *}$, Ariya Dwika Cahyono ${ }^{3}$ \\ ${ }^{1,2,3)}$ Program Studi Komputerisasi Akuntansi, Fakultas Teknologi Informasi, \\ Universitas Kristen Satya Wacana \\ Jl. Dr. O. Notohamidjojo, Salatiga 50714 \\ Email : evi.maria@uksw.edu \\ Riwayat artikel: \\ Recieved: 12-02-2020 \\ Revised: 01-09-2020 \\ Accepted: 02-09-2020
}

\section{Abstract}

The purpose of this research is to automate the inventory system of goods in SD Sidorejo Lor 06 Salatiga by developing a web based inventory system. This research focuses on designing systems ranging from listing inventory data, logging incoming goods, logging outgoing goods, performing mutation of goods, and making inventory reports. This research develops a system using the Waterfall software development model. Inventory system of goods is developed by using CodeIgniter framework and MySQL as database. Additionally, the system has two user levels: admin and user. The features of this information system include managing the data of items such as adding, editing, deleting, printing and storing data on the dashboard menu, items, transactions, reports. Hence, the aim of the automation is to solve delays and inaccuracy problem of the inventory reports in SD Sidorejo Lor 06 Salatiga. The results of the inventory system testing developed in this research is proven to speed up the process of producing inventory reports. The inventory report creation process takes only 22.30 seconds. The system has also been shown to improve the accuracy of inventory reporting in school. The system notified if the input of the number of goods out exceeded the stock of the goods owned.

Keywords: Inventory Systems, Website-Based Information Systems, Waterfall Models, CodeIgniter Framework, MySQL

\begin{abstract}
Abstrak
Tujuan riset ini adalah mengotomatisasi sistem inventarisasi barang di SD Negeri Sidorejo Lor 06 Salatiga dengan cara mengembangkan sistem inventarisasi barang berbasis website. Riset ini fokus merancang sistem mulai dari pencatatan data tempat inventaris, pencatatan barang masuk, pencatatan barang keluar, mutasi barang serta pembuatan laporan inventarisasi barang. Riset ini mengembangkan sistem menggunakan model pengembangan perangkat lunak Waterfall. Riset ini menggunakan framework codeigniter dan MySQL sebagai databasenya ketika mengembangkan sistem inventarisasi barang. Ada dua level user dalam sistem, yaitu admin dan pengguna. Sistem inventarisasi memiliki fitur mengelola data barang, yang meliputi kegitatan menambah, mengedit, menghapus, mencetak dan menyimpan data pada menu dashboard, barang, transaksi, laporan. Tujuan otomatisasi sistem inventarisasi barang adalah untuk membantu menyelesaikan masalah keterlambatan dan ketidakakuratan laporan
\end{abstract}


inventarisasi barang di SD Negeri Sidorejo Lor 06 Salatiga. Hasil pengujian sistem inventarisasi yang dikembangkan dalam riset ini terbukti mampu mempercepat proses pembuatan laporan persediaan. Proses pembuatan laporan persediaan hanya membutuhkan waktu 22,30 detik. Sistem juga terbukti mampu meningkatkan keakuratan pelaporan persediaan di sekolah. Sistem memberi notifikasi jika input jumlah barang keluar melebihi stok barang yang dimiliki.

Kata kunci: Sistem Inventarisasi, Sistem Informasi Berbasis Website, Model Waterfall, Framework Codeigniter, MySQL

\section{Pendahuluan}

Sistem inventarisasi barang merupakan suatu sistem yang memelihara catatan persediaan dan memberikan informasi bagi pihak manajemen terkait barang atau aset yang dimiliki organisasi [1]. Sayangnya, organisasi seperti sekolah belum memperhatikan sistem inventarisasi barang. Padahal jika inventaris barang dikelola dengan baik, maka kegiatan sekolah yang memerlukan dukungan barang-barang habis pakai, seperti spidol, kapur, kertas dan aset tetap, seperti komputer, printer, LCD proyektor dan lainnya dapat berjalan lancar tanpa khawatir akan terlambat dalam penyediaan dan/atau kehilangan asetnya.

Saat ini, kebanyakan instansi pendidikan di Indonesia masih menggunakan sistem inventarisasi barang secara manual. SD Negeri Sidorejo Lor 06 Salatiga adalah contoh instansi pendidikan yang melakukan pendataan inventaris barang secara manual dengan tulis tangan di buku dan kertas. Pendataan inventaris seperti ini, kurang efektif karena laporan dan data yang dihasilkan bisa jadi tidak akurat. Selain itu, pendataan secara manual, tidak efisien dari sisi waktu karena sekolah membutuhkan waktu yang lebih lama untuk menyajikan laporan inventarisasi barangnya. Oleh sebab itu, riset ini dilakukan dengan tujuan untuk mengotomatisasi sistem inventarisasi barang untuk menyingkat dan meningkatkan akurasi pelaporan barang di SD Negeri Sidorejo Lor 06 Salatiga.

Otomatisasi sistem dilakukan dengan mengembangkan sistem inventarisasi barang berbasis website (web). Aplikasi berbasis web dipilih karena aplikasi berbasis web dapat dibuat dan di implementasikan dengan cepat dan mudah [2]. Aplikasi dapat dibangun dengan cepat karena pengembang aplikasi tidak perlu lagi membuat web server, browser atau membangun jaringan internet. Aplikasi berbasis web mudah dikembangkan, mudah di update, akses informasi lebih mudah, set-up server yang lebih mudah, informasi mudah didistribusikan, serta dapat berjalan di multi platform. Riset ini akan fokus merancang sistem inventarisasi barang mulai dari pencatatan data tempat inventaris, pencatatan barang masuk dan barang keluar, mutasi barang serta pembuatan laporan inventarisasi barang di SD Negeri Sidorejo Lor 06 Salatiga .

Riset ini diharapkan memberi beberapa kontribusi. Pertama, berkontribusi bagi pengembangan ilmu di bidang Sistem Informasi karena riset ini menyediakan bukti 
implementasi teori dalam perkuliahan di dunia praktik dengan pembuatan aplikasi inventaris barang berbasis website untuk sekolah. Kedua, berkontribusi bagi sekolah, otomatisasi sistem inventaris barang berbasis website yang dihasilkan dalam riset ini dapat membantu sekolah untuk menyajikan laporan inventarisasi dengan cepat dan akurat. Ketiga, hasil riset ini dapat menjadi rujukan bagi riset yang akan datang untuk mengembangkan dan menyempurnakan aplikasi inventarisasi barang berbasis website untuk sekolah.

\section{Kajian Pustaka}

Definisi Sistem Inventarisasi Barang

Sistem adalah kelompok dari dua atau lebih komponen atau subsistem yang saling berhubungan yang berfungsi dengan tujuan yang sama [3]. Komponen pembentuk sistem merupakan kesatuan utuh yang berjalan secara teratur untuk mencapai output yang telah ditetapkan. Inventarisasi barang adalah kegiatan pengurusan, penyelenggaraan, pengaturan, pencatatan dan pendafataran barang-barang milik pribadi dan/atau organisasi. Berdasarkan dua definisi tersebut, maka sistem inventarisasi barang disimpulkan sebagai sistem yang digunakan untuk memelihara catatan persediaan/barang. Sistem tersebut akan memberikan informasi tentang aset yang dimiliki oleh organisasi [1].

\section{Pengembangan Sistem Informasi}

Hall [3] mendefinisikan sistem informasi sebagai serangkaian prosedur formula dimana data dikumpulkan, diproses menjadi informasi dan didistribusikan ke para pengguna. Sistem informasi atau aplikasi berkualitas jika perancangan fungsi dan fitur dari sistem sudah dispesifikasikan sesuai dengan kebutuhan [4]. Oleh sebab itu, sistem informasi harus dibangun dan dikembangkan dengan sistematis agar dapat menghasilkan aplikasi yang berkualitas.

Pressman [4] mengidentifikasi System Development Life Cycle (SDLC) atau dikenal dengan metode waterfall sebagai salah satu metode pengembangan sistem informasi. Metode ini mengembangkan sistem informasi secara sistematis dan berurutan saat pengembangan aplikasi. Asumsi metode ini adalah program yang dihasilkan harus sesuai dengan spesifikasinya [5]. Ada lima tahapan pengembangan sistem informasi menggunakan metode waterfall, yaitu tahap definisi kebutuhan, tahap perancangan sistem dan aplikasi, tahap implementasi dan pengujian unit, tahap integrasi dan pengujian sistem, dan tahap operasi dan pemeliharaan seperti yang disajikan pada Gbr. 1.

Selain metode waterfall, Pressman [4] juga mengidentifikasi agile sebagai metode pengembangan sistem informasi. Metode agile menggunakan metode interaktif dan inkremental. Interaksi dan personel antar anggota tim pengembang menjadi kunci keberhasilan pengembangan sistem informasi. Dalam metode ini, kolaborasi tim pengembang dengan klien lebih penting daripada negosiasi kontrak karena fungsi dan 
fitur dari sistem informasi harus terus menerus dibicarakan dan disesuaikan dengan klien. Oleh sebab itu, fokus metode agile ada pada kecepatan respon tim ketika klien menginginkan perubahan saat proses pembuatan software $[6,7]$.

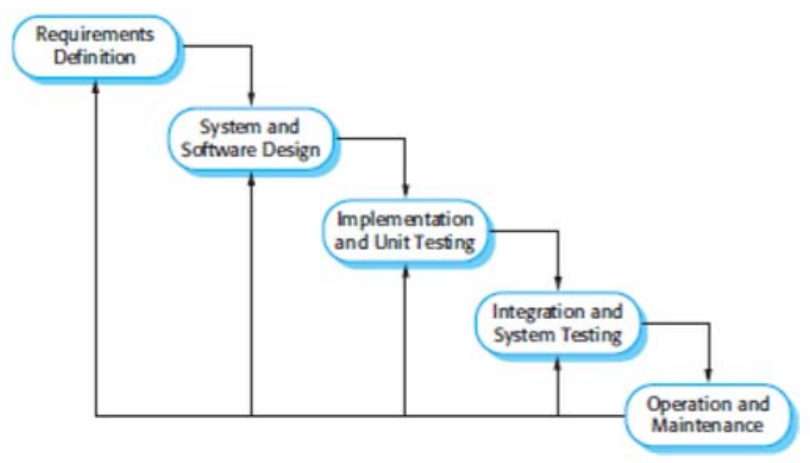

Gambar 1 Metode Waterfall

\section{Sistem Informasi Berbasis Website}

Hall [3] mendefinisikan sistem informasi berbasis website sebagai seperangkat komponen yang saling berhubungan yang berfungsi untuk mengumpulkan, memproses, menyimpan dan mentransferkan informasi dalam bentuk teks, gambar, suara, dan informasi yang dipresentasikan dalam bentuk hypertext serta dapat diakses oleh perangkat lunak untuk mendukung pembuatan kegiatan dalam organisasi dalam mencapai tujuan. Web browser melalui web client akan membaca halaman web yang tersimpan di web server melalui protocol disebut dengan HTTP (Hypertext Transfer Protocol). Ini dilakukan dalam rangka menterjemahkan dokumen hypertext agar dokumen tersebut dapat lebih mudah dipahami. Hypertext Prepocessor (PHP) merupakan bahasa pemrograman website berupa teknologi scripting. Dalam PHP, barisbaris kode diterjemahkan di server agar dihasilkan halaman website yang dinamis.

Framework codeigniter adalah salah satu framework PHP yang paling banyak digunakan oleh para programmer ketika membangun dan/atau mengembangkan aplikasi berbasis website. Framework ini bersifat open source dan menggunakan metode Model, View, Controller (MVC). Framework ini merupakan kumpulan kelas dan fungsi yang disusun secara sistematis berdasarkan kegunaan dan fungsionalitas tertentu untuk mempermudah pembuatan atau pengembangan aplikasi [5].

\section{Penelitian Terdahulu}

Riset tentang sistem inventarisasi barang di sekolah telah dilakukan dengan berbagai macam tujuan. Misalnya saja riset Oktaviani et al. [8] yang merancang dan membangun sistem inventarisasi barang berbasis web untuk membantu SMP Negeri 1 Buer dalam mengelola kegiatan peminjaman barang, kegiatan pendataan transaksi dari pembelian barang, memberikan informasi kondisi barang, dan penomoran barang. Sistem informasi dikembangkan dengan menggunakan metode waterfall dan dibangun menggunakan Sublime Text bahasa pemrograman PHP dan database MySQL Tak hanya 
Otaviani et al. [8], Siregar [9] juga telah membangun sistem informasi inventaris barang untuk membantu SMA Negeri 4 Pematang Siantar untuk mempermudah pencatatan data barang yang cukup banyak dan rumit karena sekolah masih mencatat menggunakan manual. Sistem informasi dibangun menggunakan bahasa pemrograman Microsoft Visual Basic. Net dan database MySQL.

Perbedaan riset ini dengan riset Oktaviani et al. [8] dan Siregar [9] terletak pada obyek, yaitu tempat studi kasus. Pada riset ini tempat studi kasus adalah SD Negeri Sidorejo Lor 06 Salatiga. Riset ini mengembangkan sistem inventarisasi barang hasil riset Siregar [9] dengan menambahkan harga pembelian barang. Oleh sebab itu, sistem ini tidahk hanya menyajikan kartu stok barang tetapi juga menampilkan laporan persediaan. Laporan persediaan tidak hanya berisi mutasi kuantitas barang tetapi juga menampilkan harga barang dan saldo akhir barang.

\section{Metode Penelitian}

Pendekatan Riset

Riset ini bertujuan untuk membangun aplikasi, maka riset ini dilakukan menggunakan pendekatan Research and Development (R\&D) dalam proses pembangunan dan pengembangan aplikasinya. Sistem inventarisasi barang dalam riset ini dibangun secara sistematis dan berurutan menggunakan model proses watefall seperti yang dikembangkan oleh Pressman [4]. Sistem inventarisasi barang di sekolah berbasis website dibangun menggunakan framework codeigniter. Framework tersebut dipilih karena tiga alasan. Pertama, framework codeigniter menyediakan fasilitas helper dan library sehingga membantu mempercepat dan mempermudah pengembang sistem untuk membuat pagination, session, manipulasi url dalam membuat website (web). Penggunaan framework ini memudahkan pengembang aplikasi karena aplikasi berbasis web tidak harus dibuat dari awal. Kedua, dari sisi keamanan, framework codeigniter sudah memiliki kemanan yang cukup karena user aplikasi tidak terhubung langsung dengan database. Ketiga, framework codeigniter gratis sehingga sangat cocok digunakan untuk membangun sistem di sekolah, karena proses pembangunan sistem tentunya tidak memerlukan biaya pengembangan yang tinggi. Riset ini mengggunakan MySQL sebagai database-nya.

\section{Metode Pengumpulan Data}

Riset ini menggunakan dua jenis data, yaitu sekunder dan primer. Data sekunder diperoleh dari SD Negeri Sidorejo Lor 06, Salatiga mengenai transaksi-transaksi terkait inventarisasi barang di sekolah. Sedangkan, data primer diperoleh dari hasil observasi aktivitas-aktivitas pembentuk sistem inventarisasi barang di sekolah dan hasil wawancara dengan kepala sekolah dan pegawai sekolah dengan berpedoman pada daftar pertanyaan wawancara.

Riset ini mengembangkan aplikasi menggunakan model Waterfall dengan tahapan sebagai berikut. Pertama, tahap definisi kebutuhan, yaitu proses mendefinisikan 
syarat dari kebutuhan sistem. Analisis dilakukan dengan membandingkan antara sistem inventarisasi yang sedang berjalan dengan input dan output sistem yang ideal sesuai yang diinginkan oleh pengguna aplikasi. Kedua, tahap perancangan sistem dan aplikasi, mulai dari struktur data, arsitektur aplikasi, representatif desain user interface dan coding. Tahap ini menterjemahkan kebutuhan aplikasi dari tahap analisis untuk mereperentasikan rancangan yang diimplementasikan menjadi aplikasi ditahap selanjutnya. Ketiga, tahap implementasi, yaitu tahap penerapan hasil perancangan sistem ke dalam program (web). Keempat, tahap pengujian. Pada tahap ini aplikasi akan diuji coba dengan cara menginputkan data. Tahap ini dilakukan untuk memastikan bawa setiap jalur dari aplikasi sudah berjalan optimal. Pengujian juga dilakukan dengan tujuan untuk memperoleh informasi terkait pengambilan keputusan serta penanganan kesalahan akibat dari data masukan.

\section{Hasil dan Pembahasan}

Analisis Kebutuhan

Dari hasil observasi terhadap sistem inventarisasi barang yang sedang digunakan oleh SD Negeri Sidorejo Lor 06, Salatiga, sekarang ini maka dapat diidentifikasi kelebihan dan kekurangan sistem. Sistem inventaris barang di SD tersebut, sudah memiliki prosedur dan data yang memadai untuk memenuhi kebutuhan informasi terkait inventarisasi barang di sekolah. Namun, sistem yang ada masih memiliki kekurangan dalam hal kecepatan dan keakuratan pengolahan informasi dalam bentuk laporan. Ini terjadi karena sistem inventarisasi barang disana masih manual, yaitu menggunakan buku dan kertas.

Alur pencatatan manual pada buku inventaris barang adalah sebagai berikut, staf tata usaha harus mencari dan mengambil buku inventaris barang ketika ingin mendata barang yang baru masuk atau diganti. Ketika staf tata usaha ingin mencari info tentang suatu barang, staf tata usaha harus mencarinya di buku satu persatu. Di sekolah belum tersedia media atau sistem informasi yang membuat hal hal tersebut lebih mudah dilakukan. Masalah lain muncul jika kepala sekolah tiba-tiba meminta laporan inventarisasi barang secara mendadak. Staf tata usaha tidak dapat menyediakan laporan dengan cepat dan akurat.

Berdasarkan kelemahan tersebut, maka perlu untuk dilakukan otomatisasi sistem inventarisasi barang di SD Negeri Sidorejo Lor 06, Salatiga. Otomatisasi sistem dilakukan dengan cara membangun aplikasi inventarisasi barang berbasis website. Aplikasi ini diharapkan dapat membantu memudahkan staf tata usaha untuk menyajikan laporan barang sehingga dapat meminimalkan risiko sekolah kehilangan barang serta membantu sekolah menyajikan laporan inventarisasi barang secara cepat dan akurat.

Hardware yang dibutuhkan untuk otomatisasi sistem inventaris barang di SD Negeri Sidorejo Lor 06, antara lain komputer dengan Processor Standart Dual Core atau yang diatasnya, memori minimal $2 \mathrm{~GB}$, dan harddisk dengan kapasitas minimal 500 GB. Sedangkan software yang dibutuhkan antara lain: Microsoft Visual Basic.Net 
sebagai aplikasi bahasa pemrograman, MySQL sebagai aplikasi pengolah database. Mozilla Firefox atau Google Chrome 6 dapat digunakan sebagai WEB Browser, sedangkan sistem operasi dapat menggunakan Windows 8 atau Windows 10.

\section{Perancangan Sistem}

Rancangan proses dalam riset ini dimodelkan dengan membuat diagram konteks, meliputi semua alur data dari sistem inventaris barang. Alur data tersebut dimulai dari petugas yang melakukan input data barang, input mutasi barang, input barang masuk, input barang keluar sampai kepada kepala sekolah yang menerima laporan inventaris barang. Diagram konteks disajikan pada Gambar 2.

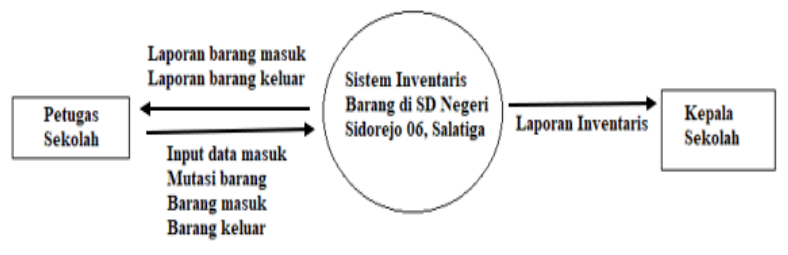

. Gambar 2 Diagram Konteks

Dalam otomatisasi sistem inventaris barang di SD Sidorejo Lor 06 Salatiga ada dua aktor yang berperan menjalankan aplikasi, yaitu petugas sekolah, yaitu staf tata usaha yang berperan sebagai admin dan pengguna aplikasi, yaitu kepala sekolah, guru, dan karyawan sekolah. Dalam aplikasi, admin memiliki hak akses untuk melakukan login, menampilkan verifikasi login sesuai hak akses, menampilkan menu home, menampilkan menu utama yang terdiri dari data barang, data transaksi, dan laporan. Admin berperan untuk menginput data kategori barang, menginput data barang, menetapkapkan saldo awal barang tiap bulannya, menginput barang masuk sesuai nota pembelian, menginput barang di transaksi barang keluar, serta mencetak laporan barang per bulan berdasarkan kategori. Use case diagram admin disajikan pada Gambar 3.

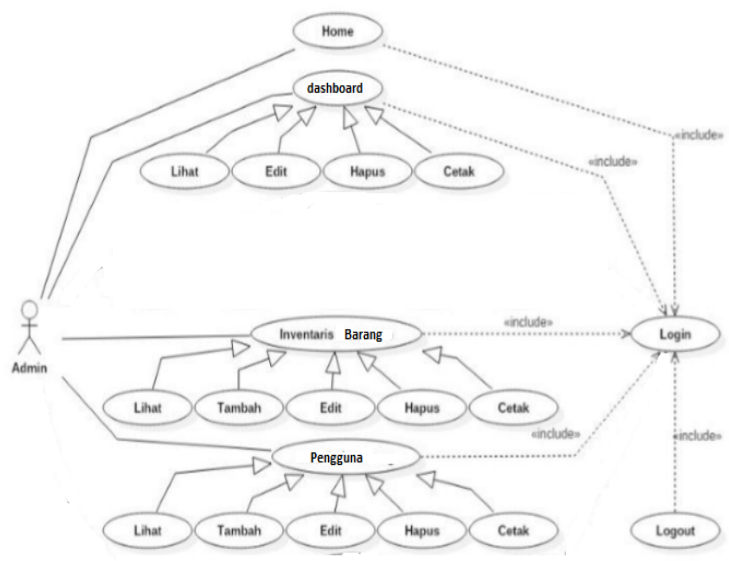

Gambar 3 Use Case Diagram Admin 
AITI: Jurnal Teknologi Informasi

Volume 17 No. 1 Februari 2020, 56-71

Pengguna, yaitu kepala sekolah, guru, dan karyawan memiliki akses menu login dan laporan dalam aplikasi sistem inventaris barang di SD Sidorejo Lor 06. Pengguna melakukan login dalam aplikasi. Setelah itu, pengguna dapat melihat laporan barang masuk dan barang keluar, serta laporan inventarisasi barang milik sekolah. Data flow diagram (DFD) level 1 terkait aktivitas inventarisasi barang di SD Sidorejo Lor 06 Salatiga disajikan pada Gambar 4. Sedangkan Entity Relationship Diagram (ERD) sistem inventarisasi barang di sekolah disajikan pada Gambar 5.

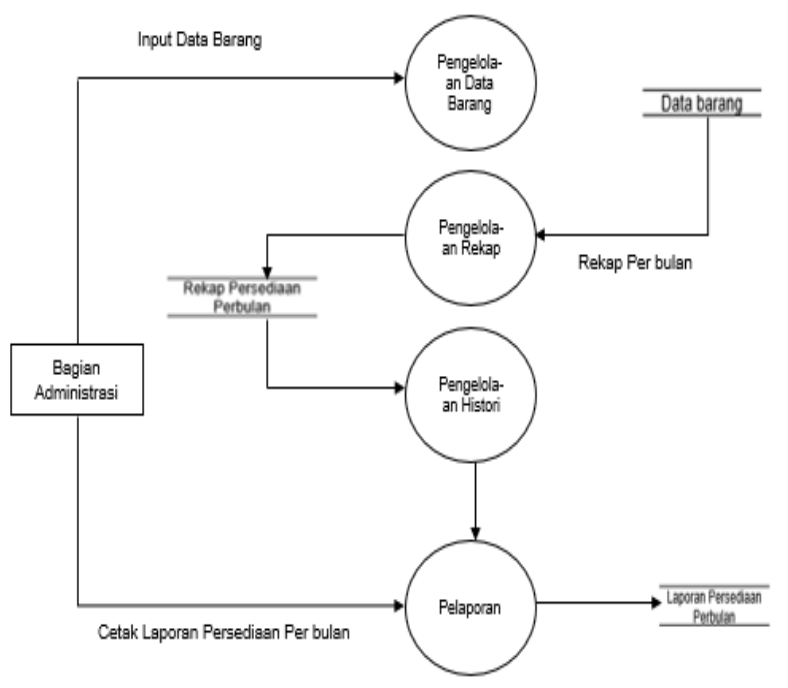

Gambar 4 DFD Level 1

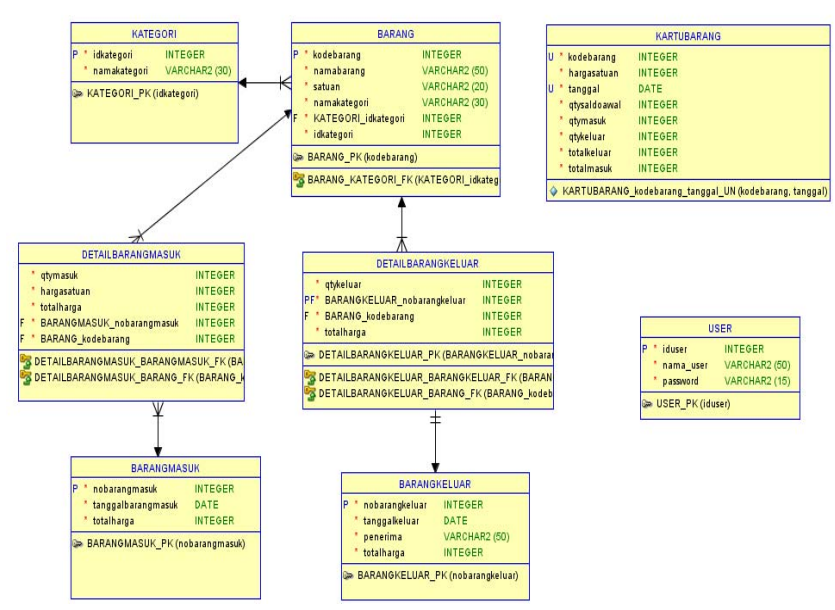

Gambar 5 Entity Relationship Diagram

Perancangan database dalam sistem inventarisasi barang di SD Negeri Sidorejo Lor 06 terdiri dari beberapa tabel. Rancangan database disajikan pada Tabel 1. 
Tabel 1 Rancangan Database

\begin{tabular}{lll}
\hline No & Tabel & Kegunaan \\
\hline 1 & User & menyimpan data user \\
2 & t_kategori & menyimpan data kategori \\
& barang & barang \\
3 & t_barang & menyimpan data barang \\
4 & t_barang masuk & $\begin{array}{l}\text { menyimpan data barang } \\
\text { masuk }\end{array}$ \\
5 & t_barang keluar & menyimpan data barang \\
& t_kartu barang & keluar \\
6 & menyimpan catatan barang \\
\hline
\end{tabular}

Rancangan proses dalam perancangan sistem, terdiri dari rancangan form input barang, form input daftar barang, form input daftar barang, form input barang masuk, form input barang keluar, rancangan laporan, dan rancangan database. Perancangan sistem yang dibuat antara lain:

1. Form input kategori barang, digunakan untuk mengisi id kategori dan nama kategori. Data yang sudah diisi akan terlihat di data kategori barang. Sedangkan, tombol simpan digunakan untuk menyimpan data. Rancangan form input kategori barang disajikan pada Gambar 6.

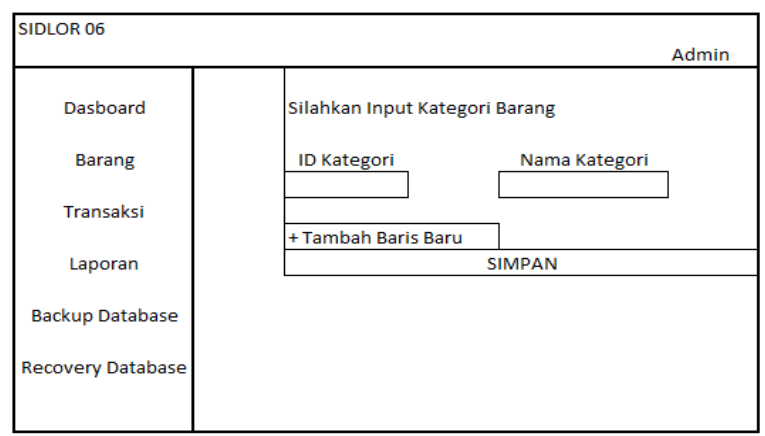

Gambar 6 Rancangan Form Input Kategori Barang

2. Form input daftar barang, digunakan untuk mengisi id kategori, kode barang, nama barang dan satuan. Form input daftar barang disajikan pada Gambar 7.

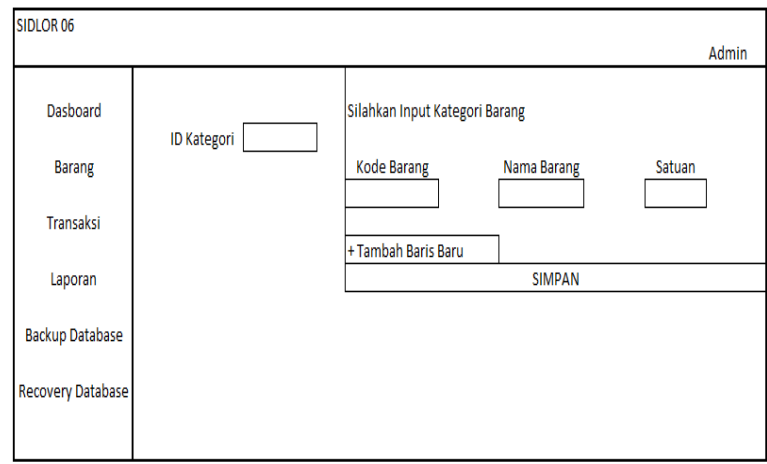

Gambar 7 Rancangan Form Input Daftar Barang 
3. Form input barang masuk, digunakan untuk menambahkan barang yang masuk. Data yang sudah diisi akan terlihat di data transaksi barang masuk. Rancangan form input barang masuk disajikan pada Gambar 8.

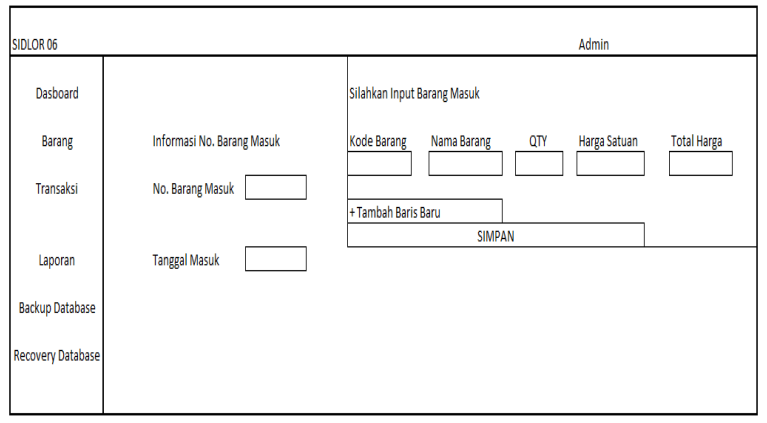

Gambar 8 Rancangan Form Input Barang Masuk

4. Form input barang keluar, digunakan untuk mengurangi jumlah barang karena ada permintaan penggunaan di sekolah. Data yang sudah diisi akan terlihat di data transaksi barang keluar. Rancangan form input barang keluar disajikan pada Gambar 9.

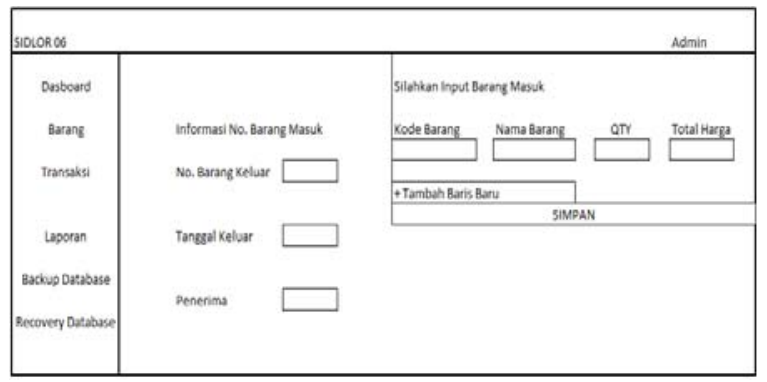

Gambar 9 Rancangan Form Input Barang Keluar

5. Rancangan laporan, adalah hasil keluaran dari sistem berupa laporan inventarisasi barang di sekolah. Gambar 10 adalah contoh rancangan laporan barang keluar hasil sistem inventarisasi barang di sekolah.

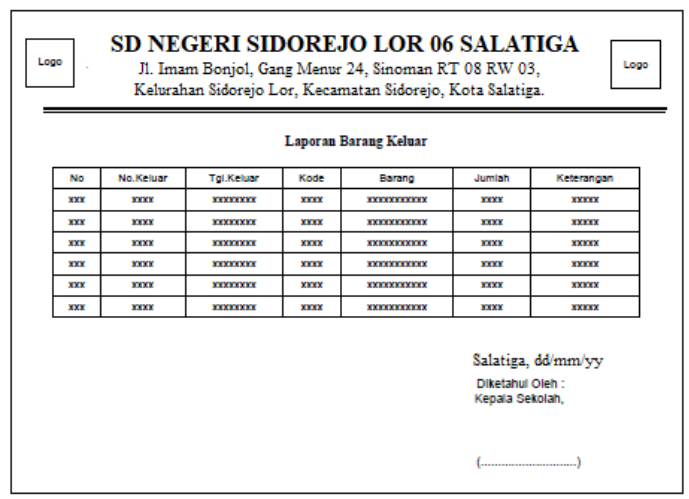

Gambar 10 Rancangan Laporan Barang Keluar 


\section{Implementasi Sistem}

Pada tahap implementasi, kode program diterjemahkan menjadi bentuk user interface. Dalam aplikasi ini ada dua level user, yaitu admin dan pengguna. Gambar 11. menyajikan halaman login bagi user. Pengguna harus login ke dalam aplikasi menggunakan user name dan password sesuai dengan kewenangan akses yang dimilikinya yang sudah diatur dalam aplikasi.

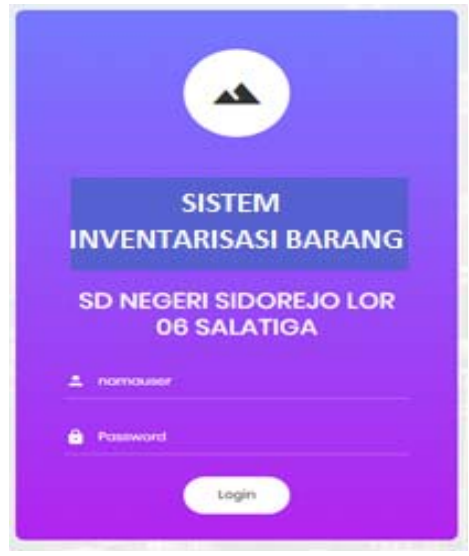

Gambar 11 Halaman Login User

Hasil implementasi rancangan sistem inventarisasi barang di SD Negeri Sidorejo Lor 06 Salatiga pada tahap sebelumnya disajikan sebagai berikut:

1. Tampilan input daftar barang dapat dilihat pada Gambar 12. Menu ini digunakan oleh admin, yaitu staf tata usaha untuk mengisi id kategori, kode barang, nama barang dan satuan.

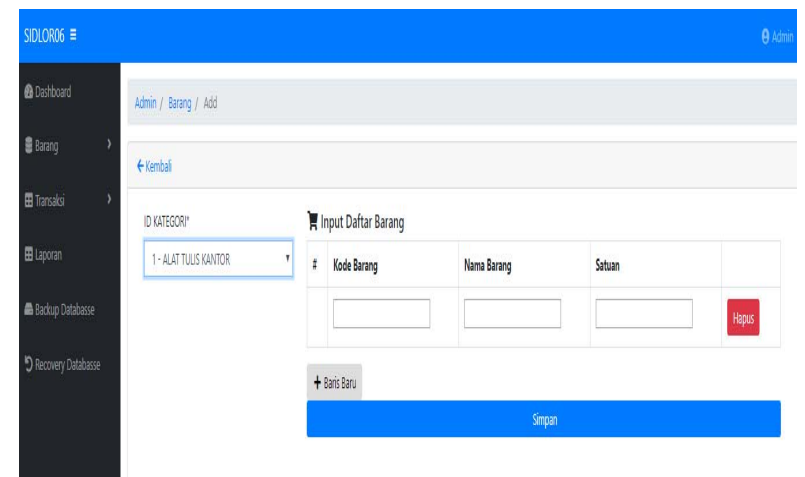

Gambar 12 Tampilan Input Daftar Barang

2. Tampilan input barang masuk dapat dilihat pada Gambar 13. Menu ini digunakan oleh staf tata usaha untuk mengisi barang yang masuk karena pembelian. 


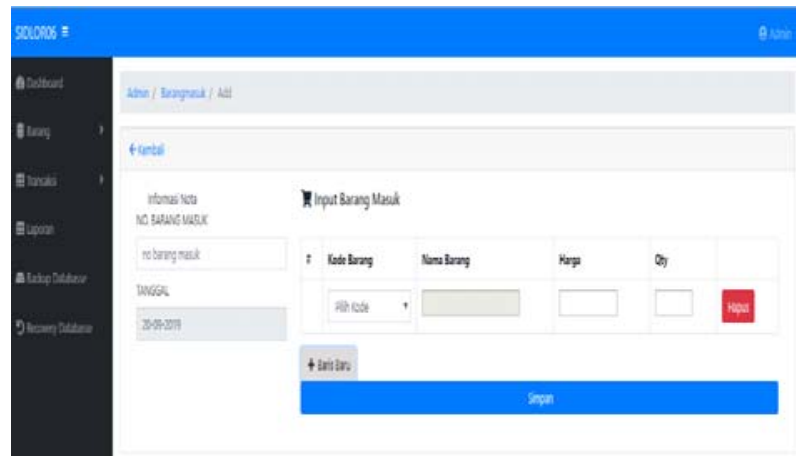

Gambar 13 Tampilan Input Barang Masuk

3. Tampilan transaksi barang masuk dapat dilihat pada Gambar 14. Halaman ini menampilkan seluruh hasil input transaksi barang masuk.

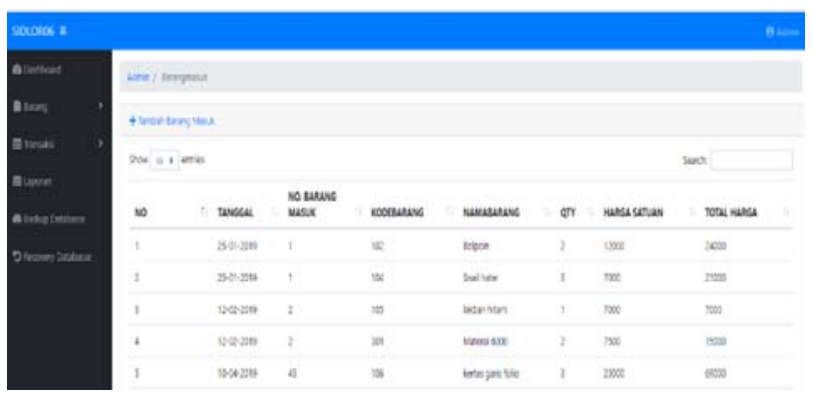

Gambar 14 Tampilan Transaksi Barang Masuk

4. Tampilan input barang keluar dapat dilihat pada Gambar 15. Menu ini digunakan oleh staf tata usaha untuk mengisi barang keluar.

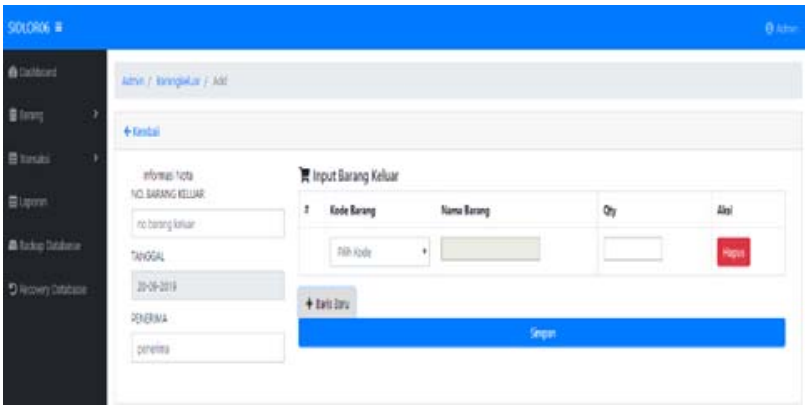

Gambar 15 Tampilan Input Barang Keluar

5. Tampilan transaksi barang keluar disajikan pada Gambar 16. Halaman ini menampilkan seluruh hasil input transaksi barang keluar. 


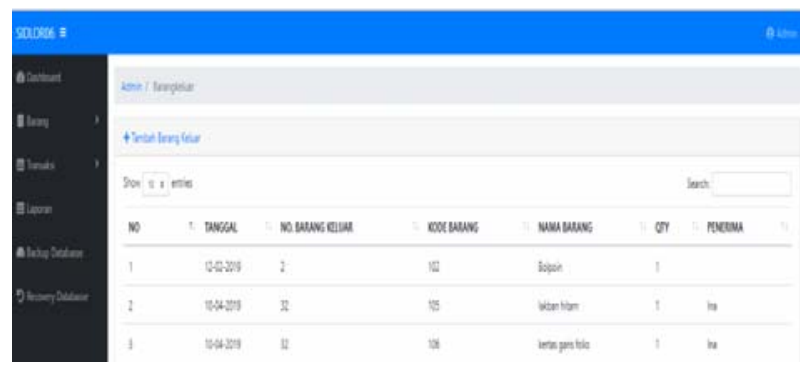

Gambar 16 Tampilan Transaksi Barang Keluar

6. Tampilan laporan disajikan pada Gambar 17. Halaman ini menampilkan hasil dari aplikasi, yaitu laporan inventarisasi barang.

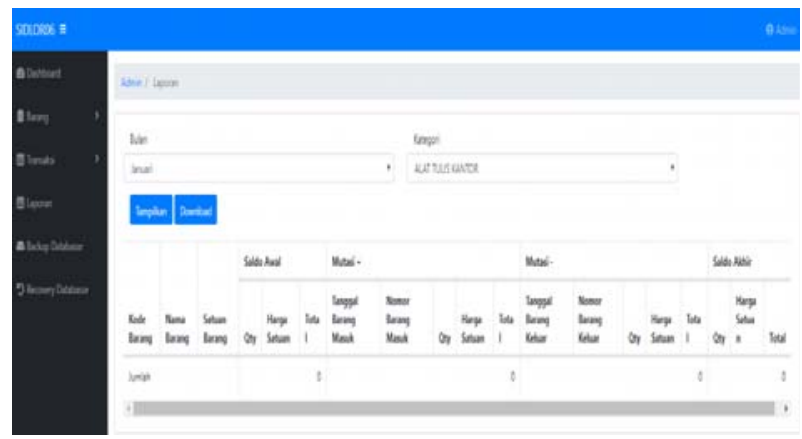

Gambar 17 Tampilan Laporan Inventarisasi Barang

Pada tahap ini, setelah kode program diterjemahkan menjadi bentuk halaman user interface maka akan diuji coba di web browser untuk mencari tahu apakah aplikasi sudah bebas dari bug atau error. Jika ditemukan bug atau error maka perbaikan kode program perlu dilakukan. Hasil pengujian menemukan bahwa setiap halaman sudah berfungsi sesuai dengan kebutuhan yang diinginkan.

\section{Pengujian Sistem}

Tahap terakhir dari proses otomatisasi sistem inventarisasi barang adalah melakukan pengujian sistem. Ada dua macam pengujian sistem. Pertama, pengujian unit (black box unit testing). Dalam metode ini, pengujian dilakukan dengan mengevaluasi cara kerja sistem yang sudah dikembangkan dalam riset ini. Ada dua pengujian yang dilakukan, yaitu pengujian tombol dan menu tampilan dalam user interface dan pengujian keakuratan sistem. Pengujian tombol dan menu tampilan dalam user interface bertujuan untuk melihat apakah tombol dan menu tampilan dalan user interface bekerja sesuai dengan yang diharapkan. Hasil pengujian disajikan pada Tabel 2. Hasil pengujian menemukan bahwa setiap tombol dan menu yang ada di dalam aplikasi yang dihasilkan telah bekerja dengan baik dan sesuai dengan rancangan yang telah dibuat. 
Tabel 2 Hasil pengujian tombol dan menu

\begin{tabular}{|c|c|c|c|c|}
\hline No & Nama & Harapan hasil & \multirow{2}{*}{$\begin{array}{l}\text { Aktual hasil } \\
\text { Tampil halaman login }\end{array}$} & Ket \\
\hline 1 & Halaman Login & $\begin{array}{l}\text { Tampil halaman } \\
\text { login }\end{array}$ & & Sah \\
\hline 2 & Input login & $\begin{array}{l}\text { Memfungsikan } \\
\text { tombol login }\end{array}$ & Login berfungsi & Sah \\
\hline 3 & Halaman dashboard & $\begin{array}{l}\text { Tampil halaman } \\
\text { dashboard }\end{array}$ & Tampil halaman dashboard & Sah \\
\hline 4 & Pilih barang & $\begin{array}{l}\text { Memfungsikan } \\
\text { tombol barang }\end{array}$ & Tombol barang berfungsi & Sah \\
\hline 5 & Pilih transaksi & $\begin{array}{l}\text { Memfungsikan } \\
\text { tombol transaksi }\end{array}$ & Tombol transaksi berfungsi & Sah \\
\hline 6 & Pilih laporan & $\begin{array}{l}\text { Memfungsikan } \\
\text { tombol laporan }\end{array}$ & Tombol laporan berfungsi & Sah \\
\hline 7 & Pilih backup database & $\begin{array}{l}\text { Memfungsikan } \\
\text { tombol backup } \\
\text { database }\end{array}$ & $\begin{array}{l}\text { Tombol backup database } \\
\text { berfungsi }\end{array}$ & Sah \\
\hline 8 & Pilih recovery database & $\begin{array}{l}\text { Memfungsikan } \\
\text { tombol recovery } \\
\text { database }\end{array}$ & $\begin{array}{l}\text { Tombol recovery database } \\
\text { berfungsi }\end{array}$ & Sah \\
\hline 9 & Tambah data & $\begin{array}{l}\text { Memfungsikan } \\
\text { tombol tambah data }\end{array}$ & $\begin{array}{l}\text { Tombol tambah data } \\
\text { berfungsi }\end{array}$ & Sah \\
\hline 10 & Hapus data & $\begin{array}{l}\text { Memfungsikan } \\
\text { tombol hapus data }\end{array}$ & $\begin{array}{l}\text { Tombol hapus data } \\
\text { berfungsi }\end{array}$ & Sah \\
\hline 11 & Edit data & $\begin{array}{l}\text { Memfungsikan } \\
\text { tombol edit data }\end{array}$ & Tombol edit data berfungsi & Sah \\
\hline 12 & Cetak data & $\begin{array}{l}\text { Memfungsikan } \\
\text { tombol cetak data }\end{array}$ & $\begin{array}{l}\text { Tombol } \\
\text { berfungsi }\end{array}$ & Sah \\
\hline 13 & Simpan data & $\begin{array}{l}\text { Memfungsikan } \\
\text { tombol simpan data }\end{array}$ & $\begin{array}{l}\text { Tombol simpan data } \\
\text { berfungsi }\end{array}$ & Sah \\
\hline
\end{tabular}

Sedangkan pengujian keakuratan sistem dilakukan dengan cara menguji jumlah stok. Jika jumlah barang keluar yang diinputkan kurang dari atau sama dengan stok barang akhir maka proses input barang keluar akan berhasil, namun tidak jika sebaliknya. Sistem akan memberi notifikasi jika stok akhir tidak mencukupi. Pengujian keakuratan sistem disajikan pada Tabel 3. Hasil pengujian menunjukkan bahwa sistem yang dikembangkan dalam riset ini akurat dalam menyajikan transaksi dan sistem memberikan notifikasi jika transaksi penginputan barang melebihi stok yang dimiliki oleh sekolah. Dari hasil pengujian unit dapat disimpulkan bahwa sistem inventarisasi barang berbasis website yang dikembangkan dalam riset ini, mampu menjawab masalah ketidakakuratan pencatatan dan pelaporan persediaan yang dialami oleh sekolah. 
Tabel 3 Pengujian keakuratan sistem

\begin{tabular}{llllll}
\hline No & Aksi dari Aktor & \multicolumn{2}{l}{ Harapan hasil } & Aktual hasil & Ket \\
\hline 1 & Input jumlah barang & Proses input & Input barang berhasil & Sah \\
& keluar kurang dari stok & berhasil dan stok & dan stok berkurang & \\
& akhir & & barang berkurang & & \\
2 & Input jumlah barang & Proses input & Input barang berhasil & Sah \\
& keluar sama dengan stok & berhasil dan stok dan stok berkurang & \\
& akhir & barang berkurang & & \\
3 & Input jumlah barang & Muncul pesan & Muncul pesan "stok Sah \\
& keluar lebih besar dari & "stok tidak tidak memenuhi" & \\
stok akhir & memenuhi” & & \\
\hline
\end{tabular}

Kedua, pengujian dengan metode keberterimaan pengguna, yaitu bagian Administrasi di SD Negeri Sidorejo Lor 06 terhadap sistem yang dikembangkan dalam riset ini. Pada metode ini dilakukan pengujian kecepatan dan keakuratan sistem. Pengujian kecepatan sistem dilakukan dengan cara membandingkan waktu pembuatan laporan persediaan antara sistem dengan manual, yaitu tulis tangan pada buku dan kertas. Hasil pengujian kecepatan sistem disajikan pada Tabel 4. Hasil pengujian menunjukkan adanya selisih waktu yang dibutuhkan dalam melakukan proses tambah data barang baik itu masuk dan keluar, serta proses menghasilkan laporan persediaan. Penggunaan sistem yang dikembangkan dalam riset ini terbukti membuat proses pelaporan barang di SD Negeri Sidorejo Lor 06 Salatiga menjadi lebih cepat. Aplikasi ini mampu menyajikan laporan persediaan dalam waktu 22,30 detik sedangkan jika dikerjakan secara manual membutuhkan waktu selama 24 menit 25 detik. Ini berarti sistem inventarisasi barang berbasis website yang dikembangkan dalam riset ini mampu menjawab masalah keterlambatan penyajian laporan persediaan yang dialami oleh sekolah.

Tabel 4 Hasil pengujian kecepatan sistem

\begin{tabular}{llllll}
\hline No & \multicolumn{2}{l}{ Proses yang Diuji } & $\begin{array}{l}\text { Hasil } \\
\text { Manual }\end{array}$ & Sistem & Keterangan \\
\hline 1 & $\begin{array}{l}\text { Tambah data } \\
\text { masuk }\end{array}$ & barang & 58,81 detik & 28,56 detik & $\begin{array}{l}\text { Sistem } \\
\text { lebih cepat }\end{array}$ \\
2 & $\begin{array}{l}\text { Tambah data } \\
\text { keluar }\end{array}$ & barang & 48,21 detik & 35,05 detik & $\begin{array}{l}\text { Sistem } \\
\text { lebih cepat }\end{array}$ \\
3 & Laporan Persediaan & $\begin{array}{l}24 \text { menit } \\
\text { 25 detik }\end{array}$ & 22,30 detik & $\begin{array}{l}\text { Sistem } \\
\text { lebih cepat }\end{array}$ \\
\hline
\end{tabular}

\section{Simpulan}

Riset ini bertujuan untuk menghasilkan otomatisasi sistem inventarisasi barang di sekolah, yaitu SD Negeri Sidorejo Lor 06, Salatiga yang dapat mempercepat penyajian laporan persediaan dan meningkatkan keakuratan laporan dengan cara membangun sistem inventarisasi barang berbasis website. Hasil pengujian sistem menemukan bahwa setiap tombol dan menu yang ada di dalam aplikasi yang dihasilkan 
telah bekerja dengan baik dan sesuai dengan rancangan yang telah dibuat. Sistem inventarisasi barang berbasis website akurat menyajikan transaksi dan laporan persediaan, serta mampu menyediakan laporan persediaan lebih cepat jika dibandingkan dengan sistem pencatatan manual yang biasa dilakukan di SD Negeri Sidorejo Lor 06, Salatiga. Aplikasi hanya butuh 22,30 detik untuk menciptakan laporan persediaan yang siap dikirim ke kepala sekolah untuk digunakan dalam proses pengambilan keputusan.

Aplikasi sistem inventarisasi barang di SD Negeri Sidorejo Lor 06 Salatiga yang dikembangkan dalam riset ini masih memiliki keterbatasan. Aplikasi belum bisa menampilkan laporan per nama barang. Saran untuk pengembangan aplikasi mendatang adalah perlu untuk menambahkan fitur laporan per nama barang, agar informasi tentang stok per barang dapat diketahui lebih cepat tanpa harus memilah-milah informasi terlebih dahulu dari laporan inventarisasi barang.

\section{Daftar Pustaka}

[1] Krismiaji, 2015, Sistem Informasi Akuntansi, edisi 4, Yogyakarta: YKPN.

[2] Elmatsani, H. M., 2017, Pengembangan Aplikasi Pengukuran TKT Online. Jurnal Rekayasa Elektrika, 13(3), 185-190.

https://doi.org/10.17529/jre.v13i3.8584

[3] Hall. A James, 2016, Accounting Information Systems, $9^{\text {th }}$ ed, South Western: Cengage Learning.

[4] Pressman, Roger S., 2015, Software Engineering, New York: McGrawHill Education.

[5] Abrahamsson, P., Salo, O., Ronkainen, J. \& Warsta, J. 2002, Agile software development methods: Review and analysis, VTT publication 478, Espoo, Finland, 107p.

[6] Hanssen G.K., Stålhane T., Myklebust T. 2018, What Is Agile Software Development: A Short Introduction. In: SafeScrum ${ }^{\circledR}$ - Agile Development of Safety-Critical Software. Springer, Cham.

[7] Sommerville, I., 2011, Software Engineering, $9^{\text {th }}$ ed. Boston: Pearson Education Inc.

[8] Oktaviani, Novi., Widiarta, I.Made., \& Nurlaily, 2018, Sistem Informasi Barang Berbasis Web pada SMP Negeri 1 Beur. Jurnal JINTEKS, 1(2), 160-168.

[9] Siregar, M. Marudut Victor, 2018, Perancangan Sistem Informasi Inventaris Barng pada Sekolah SMA Negeri 4 Pematang Siantar. IT Journal Research and Development, 3(1), 54-61. https://doi.org/10.25299/itjrd.2018.vol3(1).1899 